\title{
Potential New Therapies for Pediatric Diffuse Intrinsic Pontine Glioma
}

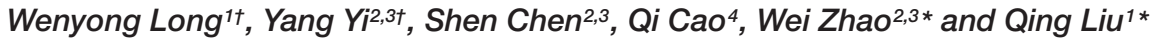 \\ 'Department of Neurosurgery, Xiangya Hospital, Central South University, Changsha, China, ${ }^{2}$ Key Laboratory for Stem Cells \\ and Tissue Engineering, Ministry of Education, Sun Yat-sen University, Guangzhou, China, ${ }^{3}$ Department of Histology and \\ Embryology, Zhongshan School of Medicine, Sun Yat-sen University, Guangzhou, China, ${ }^{4}$ Center for Inflammation and \\ Epigenetics, Houston Methodist Research Institute, Houston, TX, United States
}

\section{OPEN ACCESS}

Edited by:

Fabrizio Marcucci,

University of Milan, Italy

Reviewed by:

Angela Mastronuzzi.

Bambino Gesù Ospedale Pediatrico

(IRCCS), Italy

Robert A. Rollins,

Pfizer (United States), United States

${ }^{*}$ Correspondence:

Qing Liu

liuqingdr@csu.edu.cn

Wei Zhao

zhaowei23@mail.sysu.edu.cn

tThese authors have contributed equally to this work.

Specialty section:

This article was submitted to Pharmacology of Anti-Cancer Drugs,

a section of the journal

Frontiers in Pharmacology

Received: 08 May 2017

Accepted: 11 July 2017

Published: 25 July 2017

Citation:

Long W, Yi Y, Chen S, Cao Q Zhao W and Liu Q (2017) Potential New Therapies for Pediatric Diffuse

Intrinsic Pontine Glioma.

Front. Pharmacol. 8:495.

doi: 10.3389/fphar.2017.00495
Diffuse intrinsic pontine glioma (DIPG) is an extensively invasive malignancy with infiltration into other regions of the brainstem. Although large numbers of specific targeted therapies have been tested, no significant progress has been made in treating these high-grade gliomas. Therefore, the identification of new therapeutic approaches is of great importance for the development of more effective treatments. This article reviews the conventional therapies and new potential therapeutic approaches for DIPG, including epigenetic therapy, immunotherapy, and the combination of stem cells with nanoparticle delivery systems.

Keywords: DIPG, H3K27M, epigenetic therapy, immunotherapy, stem cells, nanoparticles

\section{INTRODUCTION}

Diffuse intrinsic pontine glioma (DIPG) is an extensively invasive malignancy of the brainstem with little notable mass effect (Helton et al., 2008; Caretti et al., 2014). These tumors account for $>80 \%$ of pediatric brainstem gliomas (Guillamo et al., 2001; Salmaggi et al., 2008; Rineer et al., 2010). Children diagnosed with DIPG have a less than 10\% 2-year survival rate (Maria et al., 1993; Rubin et al., 1998; Freeman and Perilongo, 1999; Jallo et al., 2006), making DIPG one of the most fatal diseases in children. Although occurring in all age groups, its peak age of onset is 6-7 years (Donaldson et al., 2006), with a second peak in adults aged 20-50 years (median age 34 years) (Landolfi et al., 1998; Guillamo et al., 2001; Rineer et al., 2010). DIPG is equally prevalent in both sexes (male:female $=1: 1$ ) (Recinos et al., 2007), and it has been estimated that 100-150 persons are newly diagnosed per year in the United States (Ostrom et al., 2015).

The treatment of DIPG remains unsatisfactory. These tumors cannot be fully removed surgically because of their location and infiltrative nature (Maria et al., 1993; Freeman and Perilongo, 1999). Radiation therapy (RT) remains the standard treatment, but this provides only temporary symptom relief, with no overall survival (OS) benefits. Conventional chemotherapy drugs are also ineffective. Advances in understanding its underlying biology have led to the identification of novel methods of improving patient survival. This review describes traditional and new potential treatments of DIPG.

\section{GENETIC AND EPIGENETIC ALTERATIONS OF DIPG}

DNA is well organized into nucleosomes containing 147 base pairs, which are wrapped around histone octamers containing two copies each of histones H2A, H2B, H3, and H4 (Esteller, 2005). The N-terminal ends of histones contain lysine $(\mathrm{K})$ and arginine $(\mathrm{R})$ residues, which can be 
posttranslationally modified (e.g., lysine and arginine methylation, histone lysine acetylation). These modified histones can regulate transcription. Notably, several lysine residues in histone $\mathrm{H} 3$, namely, $\mathrm{H} 3 \mathrm{~K} 4, \mathrm{~K} 9, \mathrm{~K} 27, \mathrm{~K} 36$, and $\mathrm{K} 79$, have been found to be methylated and have been comprehensively studied (Barski et al., 2007). Importantly, the missense mutation Lys27 Met (K27M) in the genes encoding histones H3.3 (H3F3A) and H3.1 (HIST3H1B) has recently been identified in pediatric DIPG (Khuong-Quang et al., 2012; Sturm et al., 2012; Wu et al., 2012; Bjerke et al., 2013). Nearly $80 \%$ of DIPGs harbor H3K27M mutation, with the presence of mutation inversely correlated with reduced median OS. These findings suggest that epigenetic dysregulation is of great importance for the pathogenesis of DIPGs. Complete understanding of epigenetic alterations in DIPG (Figure 1 and Table 1) presents options for exploring new therapeutic approaches involving the pharmacological targeting of epigenetic pathways.

\section{Histone Methylation and Chromatin Machinery}

Histones deposited during DNA synthesis are the key protein components of chromatin. Selective or reversible modifications of these proteins are responsible for conformational transitions between transcriptionally active and inactive chromatin states. In mammals, three isoforms (H3.1, H3.2, and H3.3) of histone H3 share highly conserved amino acid sequences. H3.1 and H3.2, which are replication dependent, are synthesized and deposited on DNA during S phase, whereas H3.3 synthesis and DNA deposition continue throughout the cell cycle (Maze et al., 2013; Skene and Henikoff, 2013). Posttranslational modifications, such as methylation at the $\mathrm{N}$-terminal of histone $\mathrm{H} 3$, play crucial roles in DNA replication, repair, and transcription (Barski et al., 2007). In addition, the extent of methylation of lysine residues (mono-, di-, or tri-methylation) on histone $\mathrm{H} 3$ can alter the functional properties of DNA (Broniscer et al., 2010). Notably, methylation of histone H3 lysine 27 (H3K27) is particularly influential in determining the expression of cancer-related genes.

In general, H3K27 methylation status is determined by the methyl-transferase activity of EZH2 and the de-methylation activities of JMJD3/KDM6B and UTX/KDM6A (Agger et al., 2007). However, up to $80 \%$ of DIPGs harbor a mutation in canonical $\mathrm{H} 3$ variants ( $\mathrm{H} 3.1$ and $\mathrm{H} 3.3$ ) that encode HIST1H3B or H3F3A, leading to the expression of H3K27M (Buczkowicz et al., 2014; Fontebasso et al., 2014; Taylor et al., 2014) H3K27M has been shown to bind to EZH2, a catalytic subunit of polycomb repressive complex 2 (PRC2), and inhibit PRC2 function. This can result specifically in globally reducing $\mathrm{H} 3 \mathrm{~K} 27 \mathrm{me} 3$ levels and altering the transcription of various genes, a process that may partially account for the associations of histone $\mathrm{H} 3$ mutations with a more

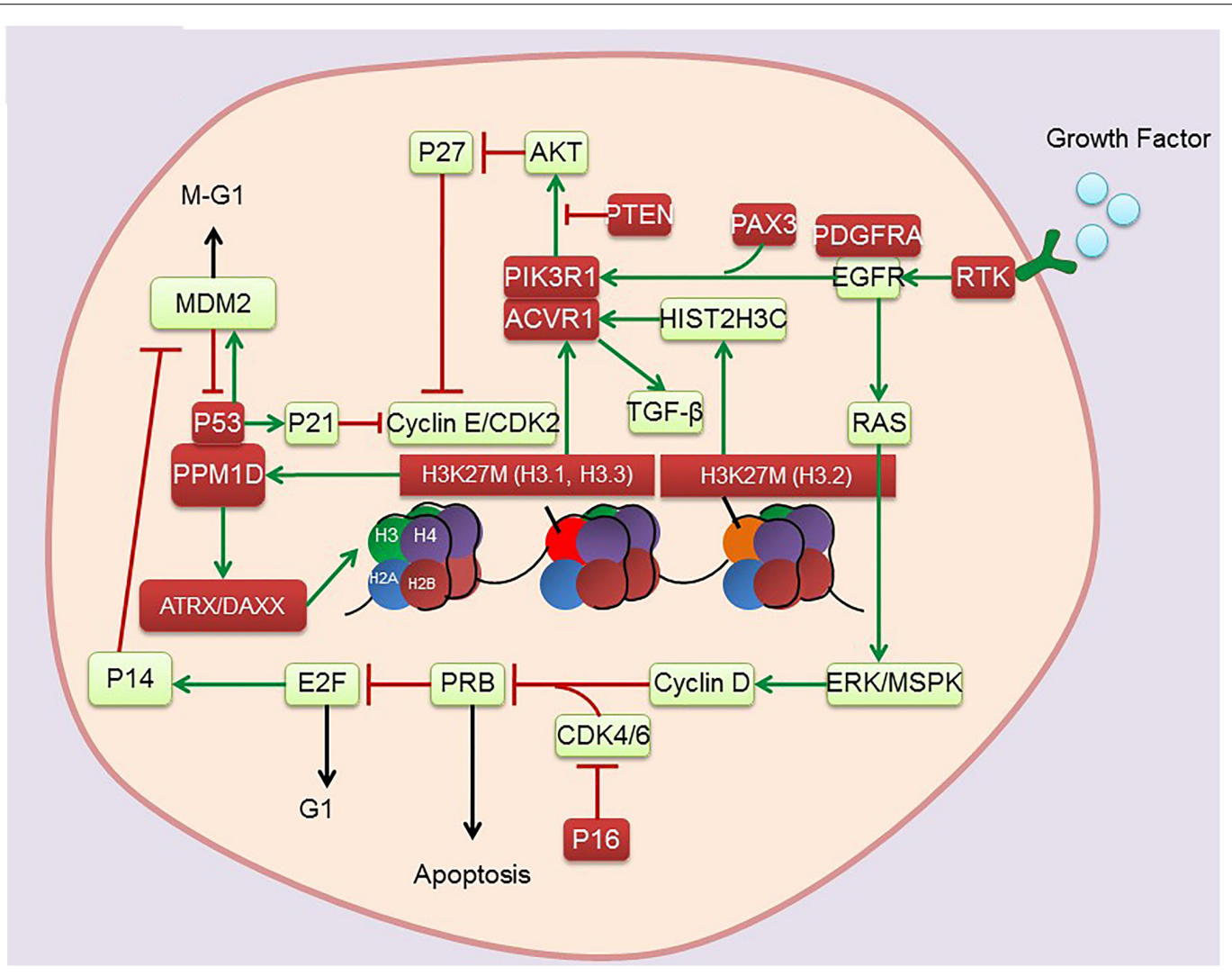

FIGURE 1 | Genetic and epigenetic alterations found in DIPG. Red boxes indicate mutations. 
TABLE 1 | Genetic and epigenetic alterations found in DIPG.

\begin{tabular}{|c|c|c|c|c|c|}
\hline \multicolumn{2}{|c|}{ Genes mutation in DIPG } & \multicolumn{2}{|c|}{ Prevalence } & \multirow{2}{*}{$\begin{array}{l}\text { Co-occurrence } \\
\text { Co-occurrence with TP53 (75\%), PDGFRA (40\%), ACVR1 (30\%), PPM1D (22\%) }\end{array}$} & \multirow{2}{*}{$\begin{array}{l}\text { Epigenetic dysregulation } \\
\text { Hypomethylation }\end{array}$} \\
\hline H3K27M & H3F3A & $63 \%$ & $84 \%$ & & \\
\hline & HIST1H3B or & $21 \%$ & & & \\
\hline & HIST1H3C & & & & \\
\hline \multicolumn{2}{|l|}{ TP53 } & $55 \%$ & & Co-occurrence with H3K27M (59\%) & N/A \\
\hline \multicolumn{2}{|l|}{ ACVR1 } & $24 \%$ & & Co-occurrence with HIST1H3B & Hypomethylation \\
\hline \multicolumn{2}{|l|}{ PDGFRA } & $16 \%$ & & Co-occurrence with H3F3A & Hypomethylation \\
\hline \multicolumn{2}{|l|}{ PPM1D } & $15 \%$ & & Co-occurrence with H3F3A & Hypomethylation \\
\hline \multicolumn{2}{|l|}{ ATRX/DAXX } & $9 \%$ & & Co-occurrence with HIST1H3B (100\%) & Chromatin remodeling \\
\hline \multicolumn{2}{|l|}{ MYCN/MYC } & $7.70 \%$ & & N/A & Hypermethylation \\
\hline \multicolumn{2}{|l|}{ Others } & $\mathrm{N} / \mathrm{A}$ & & $N / A$ & N/A \\
\hline
\end{tabular}

aggressive clinical course and poorer OS rates (Lewis et al., 2013).

Mutant IDH1 can directly establish CpG island methylator phenotype_(CIMP) and induce extensive DNA hypermethylation. In addition, mutant IDH1 also increases levels of $\mathrm{H} 3 \mathrm{~K} 9 \mathrm{me} 2, \mathrm{H} 3 \mathrm{~K} 27 \mathrm{me} 3$, and H3K36me3. Mechanistically, expression of mutant IDH1 results in production of 2hydroxyglutarate $(2-\mathrm{HG})$, which is the competitive antagonist of 2-Ketoglutaric acid (2-KG). 2-HG subsequently leads to activity inhibition of 2-KG dependent DNA dioxygenases, such as TETs (Turcan et al., 2012). Thus, IDH1 mutations result in the inhibition of histone lysine demethylases, IDH1-mutated tumors tend to be globally hyper-methylated compared with tumors without IDH1 mutations (Fathi and Abdel-Wahab, 2012; Zhang et al., 2014). In contrast to H3K27M tumors, median OS is higher in tumors with than without IDH1 mutations. Thus, strategies opposite to those used to treat hypomethylated DIPGs with H3K27M mutations will be needed to treat hypermethylated DIPGs with IDH1 mutations.

\section{H3.3-ATRX-DAXX Chromatin Remodeling Complex}

ATRX and DAXX constitute two subunits of the H3.3-ATRXDAXX chromatin remodeling complex at telomeres and other genomic sites. ATRX mutations (loss of function) have been reported in $9 \%$ of DIPGs, but are not prevalent in lowgrade gliomas in children (Zhang et al., 2013). Moreover, somatic mutations in the ATRX-DAXX complex have been observed to co-occur with $\mathrm{K} 27 \mathrm{M}$ mutations with a frequency of co-occurrence reported as $8 \%$ in pontine gliomas (Solomon et al., 2016). Interestingly, ATRX mutations are more frequent in children diagnosed with DIPG at an older age (KhuongQuang et al., 2012). Depletion of ATRX and/or DAXX reduces the incorporation of $\mathrm{H} 3.3$ into heterochromatic regions, leading to the destabilization of telomeres and promoting alternative lengthening of telomeres (ALT) (Heaphy et al., 2011). ALT is the predominant mechanism of telomere maintenance in the presence of $\mathrm{H} 3 \mathrm{~F} 3 \mathrm{~A}$ and ATRX in pediatric GBMs (Schwartzentruber et al., 2012). Moreover, H3K27M upregulation of HIPK1 may increase the translocation of DAXX, which may in turn alter chromatin and telomere structure, causing aberrant gene expression in DIPGs (Saratsis et al., 2014).
Gain of function in the H3.3-ATRX-DAXX axis may also guide drug development for DIPG.

\section{H3K27M Crosstalk with Histone Acetylation and DNA Methylation}

Current analysis of histone methylation in DIPGs cannot fully determine the relationships between histone modifications and DIPG development. Over-acetylation of H3K27 was found to be mutually exclusive of K27 mutation. Thus, increased K27 acetylation was found to be accompanied by decreased K27me3 in K27M mutant glioma cells (Lewis et al., 2013), a finding confirmed in the Drosophila melanogaster model (Herz et al., 2014). Furthermore, PRC2 loss-of-function phenotypes in the Drosophila model resembled the reduced H3K27 methylation and depression of PRC2 target genes in DIPGs. These findings suggested that K27 acetylation may also be responsible for glioma formation and that K27 methylation and acetylation should be studied in juxtaposition. Investigations regarding the relationships between $\mathrm{K} 27$ modifications and tumor development should therefore include screening for enzymatic activities responsible for all types of K27 modifications. The elevated level of H3K27 acetylation observed in DIPGs suggests that inhibition of histone deacetylase (HDAC) may potentially benefit patients.

In addition to histone modifications, DNA methylation plays a key role in coordinating gene expression and chromatin remodeling in brain tumors. DNA methylation, which occurs at cytosine residues of $\mathrm{CpG}$ dinucleotides, is usually associated with gene silencing (Schubeler, 2015). DNA methylation profiles across all tumor sites in DIPG tissues were shown to be associated with alterations in a specific histone 3 variant (Fontebasso et al., 2014). In mammals, DNA methylation occurs primarily at the 5-position of cytosines $(5 \mathrm{mC})$ in $\mathrm{CpG}$ dinucleotides. Methylated cytosines at gene promoters are usually associated with transcriptional silencing. Notably, Ten Eleven Translocation (TET) enzymes can convert $5 \mathrm{mC}$ to 5hydroxymethylcytosine (5hmC) dependent on alpha-ketoglutarate $(\alpha-K G)$. Previous studies revealed that loss of $5 \mathrm{mC}$ leads to a redistribution of PRC2 complexes, indicating that $5 \mathrm{mC}$ could affect interaction between PRC2 and chromatin. Aberrant recruitment of PRC2 to DNA associated with $5 \mathrm{hmC}$ may shift PRC2 away and promote an active transcriptional state. Low levels of H3K27me3 and $5 \mathrm{mC}$ and higher levels of $5 \mathrm{hmC}$ were found to be more frequent in 
DIPGs with H3K27M than in extrapontine GBMs. Generally, high levels of $5 \mathrm{hmC}$ have been shown to be a feature of terminally differentiated cells (Haffner et al., 2011) and to be associated with a less aggressive phenotype (Orr et al., 2012). However, dysregulation of histone and cytosine methylation is unique to DIPGs, suggesting putative crosstalk between histone and DNA methylation pathways, thereby altering transcriptional activity (Bender et al., 2013). Thus, the finding, that DNA methylation profiles are associated with the K27M mutation regardless of tumor location, supports its role in driving the epigenetic phenotype and establishes a foundation for treatment with specific inhibitors of DNA methylation (Morales and Kieran, 2017).

\section{Bromodomain and Extraterminal (BET) Associated Genes Regulated MYCN Pathways}

Bromodomain and extraterminal (BET) family proteins are associated with transcriptional activation through their interactions with acetylated chromatin, as well as playing key roles as epigenetic regulators (Dhalluin et al., 1999). BET proteins regulate the expression of certain significant oncogenes including those genes involved in the cell cycle and apoptosis pathways. Elevated H3K27 acetylation has also been associated with increased levels of bromodomain containing proteins 1 (BRD1) and 4 (BRD4) (Herz et al., 2014). Measurement of CpG island methylation allows identification of a subgroup of DIPGs with high-level amplification of the MYCN pathways in DIPG (Buczkowicz et al., 2014; Taylor et al., 2015). Despite difficulties in directly targeting MYCN, the bromodomainmediated inhibition of MYCN attenuated tumor growth and induced apoptosis, conferring a survival advantage in three in vivo models of neuroblastoma (Puissant et al., 2013). Due to the potential of BET as an epigenetic target, small molecule inhibitors of BET proteins are being broadly screened (Wadhwa and Nicolaides, 2016). It is worth noting that the majority of the heterotypic H3K27M-K27ac nucleosomes colocalize with bromodomain proteins at the loci of actively transcribed genes. Piunti et al. (2017) found that treatment of DIPG cells with BET bromodomain inhibitor JQ1 significantly suppressed the tumourigenicity in vivo, thus identifying this class of compounds as a novel epigenetic therapy to overcome DIPG.

\section{PROGESS IN TRADITIONAL TREATMENTS FOR DIPG}

Diffuse intrinsic pontine glioma is almost invariably fatal with a mean OS of 9-12 months from the time of diagnosis. RT provides temporary symptom relief but no OS benefits. Several types of adjuvant therapy, such as small molecules targeting tumor proliferation, apoptosis, the cell cycle, angiogenesis, DNA repair, and radiation sensitizers have been studied, but none has had any promising impact on patient outcomes. Although recent advances in understanding the anatomic details of brainstem structures and the availability of neuroimaging monitoring may warrant biopsy at diagnosis and subtotal resection in some patients, surgical resection remains uncommon. Combinations of traditional therapy with epigenetic therapy, immunotherapy and nanotechnology show exciting therapeutic potential.

\section{Radiation Therapy}

Treatment with a total radiation dose of 54-60 Gy over 6 weeks was found to result in temporary symptom relief in patients with pediatric DIPG, as well as delaying tumor progression in about $70-80 \%$. Re-irradiation significantly increases risks of radiation toxicity at doses $>64$ Gy (Bartels et al., 2011) without improving survival outcomes (Fontanilla et al., 2012; Susheela et al., 2013). Because DIPG biology appears to shift from initial diagnosis to tumor progression (Wolff et al., 2012), re-planning of therapy may be warranted (Chris Beltran, 2011).

Treatment of 16 pediatric brainstem glioma patients with a combination of interferon-beta, nimustine (ACNU), and radiation (IAR therapy) resulted in a median OS of 15.7 months, a marked improvement compared with the natural course of this disease (Wakabayashi et al., 1992). No further clinical benefit was achieved with alternative radiation strategies or from combinations of radiation with radiation sensitizers (Robison and Kieran, 2014; Roos and Smith, 2014), such as temozolomide (Sirachainan et al., 2008), capecitabine (Kilburn et al., 2013), panobinostat (Hennika et al., 2017), and tipifarnib (HaasKogan et al., 2011). A Children's Oncology Group phase I study indicated that depletion of DNA repair enzymes with motexafin gadolinium (MGd)-enhanced radiation sensitivity about twofold (Bradley et al., 2008). However, this finding was not confirmed in a subsequent Children's Oncology Group phase II Study (Bradley et al., 2013). Other radiation sensitizers remain to be tested, including the PARP1 inhibitor niraparib (Chornenkyy et al., 2015), the bromodomain inhibitor JQ1, the NOTCH signaling inhibitor MRK003 (Taylor et al., 2015), the CDK4/CDK6 inhibitor PD-0332991 (Barton et al., 2013), and the G2 cell-cycle checkpoint WEE1 kinase inhibitor MK-1775 (Caretti et al., 2013). Although in vitro and in vivo results indicate that these compounds may be effective radiation sensitizers for DIPG, multi-center clinic trials are required to validate these findings.

\section{Targeted Therapy}

The multistep development of human tumors includes the gain of eight biological capabilities: sustained proliferative signaling, evasion of growth suppressors, resistance to cell death, enabling of replicative immortality, induction of angiogenesis, activation of invasion and metastasis, reprogramming of energy metabolism and evasion of immune system destruction (Hanahan and Weinberg, 2011). Since the introduction of mechanism-based molecular targeted therapies to treat DIPG, more than 250 clinical trials aimed at different biological capabilities of DIPG have been initiated. The gene encoding the receptor tyrosine kinase (RTK) platelet-derived growth factor receptor alpha (PDGFRA) is one of the most frequently amplified genes in DIPGs (Paugh et al., 2010, 2013; Zarghooni et al., 2010; Barrow et al., 2011; Puget et al., 2012), with activating mutations in PDGFRA observed in 10\% of DIPGs (Balss et al., 2008). Agents 
targeting PDGFR, such as imatinib and dasatinib, have exhibited low antitumor effects in clinical trials (Truffaux et al., 2015). The gene encoding epidermal growth factor receptor (EGFR) is also overexpressed in pediatric brain tumors (Bredel et al., 1999; Gilbertson et al., 2002), suggesting that targeting of EGFR may have benefits for patients. Trials of anti-EGFR drugs, such as nimotuzumab (Bartels et al., 2014), gefitinib (Pollack et al., 2011), and erlotinib (Geoerger et al., 2010), have benefits in a small subset of DIPG patients. Other trials have targeted DNA repair, using the PARP1 inhibitors veliparib, olaparib, and niraparib (Chornenkyy et al., 2015), the anti-MGMT agent O6-benzylguanine (Warren et al., 2012), and MGd. Additional trials have tested the multi-kinase inhibitor BMS-754807 (Halvorson et al., 2015), the CDK4/CDK6 inhibitor PD-0332991, the WEE1 kinase inhibitor MK-1775, the antiangiogenic agent bevacizumab, a monoclonal anti-VEGF antibody (Liu et al., 2009; Gururangan et al., 2010), and the farnesyltransferase inhibitor tipifarnib (Haas-Kogan et al., 2011). To date, however, none of these trials has shown efficacy in DIPG. These treatment failures may be caused by the presence of drug efflux transporters, the ability of the tested drugs to cross the blood-brain barrier (BBB), or other resistance mechanisms (Veringa et al., 2013). Alternative methods of drug delivery, such as nanoparticle deliver systems, may offer new possibilities for the treatment of pediatric DIPG.

\section{Surgical Biopsy and Resection}

The brainstem region has long been considered a "forbidden area" for surgery. The shortage of readily available DIPG tissue samples for molecular analysis has hindered the investigation of these tumors and their molecular biology. Due to the potential risks of the surgical procedure and poor benefit for patients, biopsy of DIPG was abandoned by the majority of neurosurgical teams in the last 20 years. However, with the development of novel molecular genetic techniques and existence of various molecular signatures which indicated for different therapeutic schemes and agents, the role of stereotactic biopsy during the treatment of DIPG was gradually refocused in the recent years (Puget et al., 2015; Carai et al., 2017). Meanwhile, studies of brainstem anatomy have revealed 12 "safe entry zones" in the brainstem, including the perioculomotor (Bricolo et al., 1991); lateral mesencephalic sulcus; suprafacial (Kyoshima et al., 1993), interfacial (Bricolo and Turazzi, 1995), and lateral (Lawton et al., 2006) sulcus limitans; periolivary; posterior median sulcus; infraclavicular and supraclavicular areas; and the peritrigeminal, infrafacial, and supratrigeminal zones (Cavalheiro et al., 2015). However, it is nearly impossible to surgically resect intrinsic gliomas completely due to diffuse malignant infiltration into white matter tracts; hence, surgery is still not recommended approach for pediatric DIPG.

\section{NEW POTENTIAL TREATMENTS FOR DIPG}

\section{Epigenetic Therapy}

Growing evidence suggests that epigenetic alterations, either alone or in combination with gene mutations, are significantly associated with DIPG development and progression. The high frequency of $\mathrm{H} 3 \mathrm{~K} 27 \mathrm{M}$ mutations in DIPG, resulting in the marked reduction of $\mathrm{H} 3 \mathrm{~K} 27 \mathrm{me} 3$ levels, has led to the development of novel therapeutic strategies targeting enzymes responsible for chromatin modifications (Figure 2).

\section{Histone Methylase and Demethylase Inhibitors}

Up to $80 \%$ of DIPGs harbor a mutation in H3K27M (Schwartzentruber et al., 2012; Wu et al., 2012; Buczkowicz et al., 2014; Fontebasso et al., 2014; Taylor et al., 2014), resulting in global reductions in H3K27me3 levels (Lewis et al., 2013). H3K27me3 levels are regulated by the H3K27 methylating enzyme EZH2 and the de-methylating enzyme JMJD3/KDM6B. $\mathrm{EZH} 2$ was found to be highly expressed in a variety of solid tumors, including colon (Tan et al., 2007) and prostate (Varambally et al., 2002, 2008) cancers and hematological malignancies (Morin et al., 2010, 2011). Moreover, high EZH2 expression correlated with poor median OS (Helin and Dhanak, 2013), indicating that EZH2 is a potential therapeutic target for H3K27M-mutant DIPG. However, treatment of pediatric GBM/DIPG cells harboring either a $\mathrm{H} 3.3$ mutation or a $\mathrm{H} 3$ wild type with the EZH2 inhibitor EPZ-6438 had little effect on these cells (Wiese et al., 2016), indicating that EZH2 inhibition alone might be ineffective in patients with DIPG. In contrast, treatment of DIPGs having a H3K27M mutation with the EZH2 inhibitor tazemetostat resulted in global loss of $\mathrm{H} 3 \mathrm{~K} 27 \mathrm{me} 3$, several genes retained $\mathrm{H} 3 \mathrm{~K} 27 \mathrm{me} 3$, with residual PRC2 activity required for the proliferation of H3K27M-expressing DIPGs (Mohammad et al., 2017). The difference between these two studies may have been due to sample bias, indicating a need for additional studies.

As H3K27M DIPG cells with reduced di- and trimethylation (H3K27me2 and H3K27me3) are transcriptionally more active, another potential strategy has focused on inhibiting the Jumonjidomain demethylase JMJD3, a key enzyme responsible for the demethylation of H3K27 (Lewis and Allis, 2013). Treatment of H3K27M-expressing DIPG cells and brainstem glioma xenografts with the GSK-J4, an inhibitor of JMJD3 demethylase, resulted in complete growth inhibition, along with increased K27 methylation and a subsequent decrease in gene expression (Hashizume et al., 2014). This effect was further enhanced by panobinostat (Bagcchi, 2015; Grasso et al., 2015), an agent approved by the FDA for other indications. At present, clinical trials are being planned to test single and combination therapy in patients with DIPG (Staedtke et al., 2016).

\section{Histone Deacetylase Inhibitors}

Histone deacetylase inhibitors prevent histone deacetylation, thereby facilitating an open chromatin structure and resulting in gene activation. The pan-HDAC inhibitor, vorinostat, showed high activity against high-grade gliomas and other pediatric central nervous system (CNS) tumors (Milde et al., 2011; Kitange et al., 2012). Screening of DIPG cells with 83 small molecules identified a multi-HDAC inhibitor panobinostat, which has been developed for the treatment of various cancers (Ellis et al., 2008). This agent showed the highest anti-DIPG activity in vitro, an order of magnitude better than vorinostat (Grasso et al., 2015). Indeed, a dose-dependent increase in global H3 acetylation 


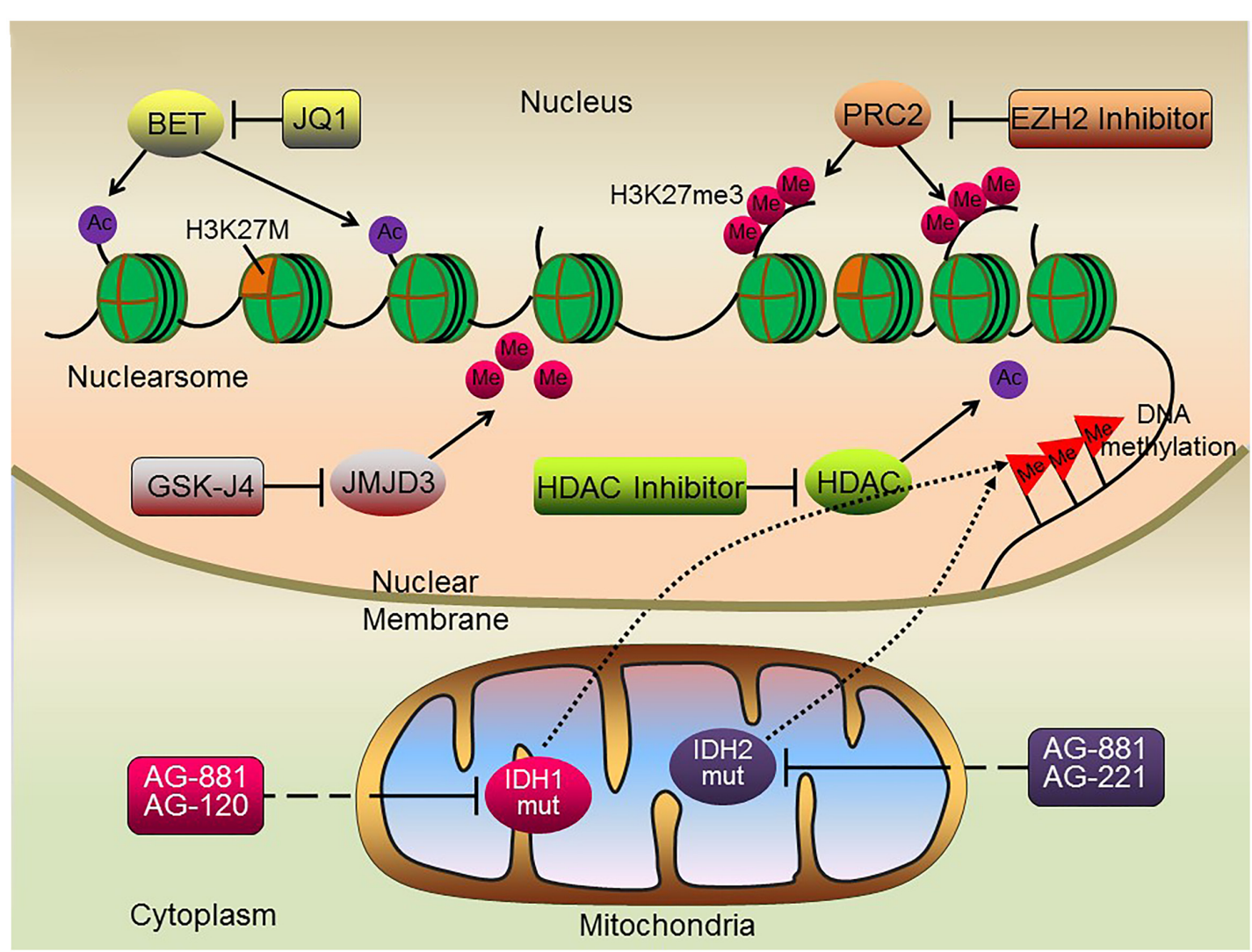

FIGURE 2 | Schematic illustration of potential epigenetic therapies for DIPG. Histone methylase and demethylase inhibitors, histone deacetylase inhibitors, BET protein inhibitors and DNA methylation inhibitors may all serve as potential therapeutic targets suppressing tumorigenesis of H3K27M DIPGs.

and $\mathrm{H} 3 \mathrm{~K} 27$ trimethylation following panobinostat treatment suggested that this drug partially rescued the H3K27M-induced hypotrimethylation phenotype (Grasso et al., 2015). Increased $\mathrm{H} 3 \mathrm{~K} 27$ trimethylation revealed that poly-acetylation of the H3 $\mathrm{N}$-terminal tail can rescue K27M-induced inhibition of the PRC2 (Brown et al., 2014) and subsequently normalize the K27M gene expression signature, further reducing the expression of genes targeted by the oncogene MYC (Grasso et al., 2015). In addition to panobinostat being tested in clinical trials of adults with brain tumors (NCT01324635, NCT00848523), the side effects and optimal dose of panobinostat are currently being tested for the treatment of younger patients with DIPG (NCT02899715, NCT02717455). Concomitant treatment with panobinostat and reirradiation for patients with DIPG showed promising effects (Wang et al., 2017). Panobinostat was shown to reduce the expression of oncogenes, and to increase global $\mathrm{H} 3$ acetylation and $\mathrm{H} 3 \mathrm{~K} 27$ trimethylation, in DIPG cells. A combination of panobinostat and GSK-J4 showed a synergistic effect against DIPG cells, indicating a need for studies of the anti-tumor activities exhibited by multiple histone modifiers.

\section{DNA Methylation Inhibitor}

Approximately 25\% of brainstem gliomas harbor IDH mutations (Zhang et al., 2014), leading to global hyper-methylation and suggesting that hypo-methylating agents may be therapeutically effective in patients with DIPG. Two preclinical studies have shown that DNA hypo-methylating agents, including decitabine and 5-azacytidine, suppressed the growth of IDH1-mutant tumor cell lines (Borodovsky et al., 2013; Turcan et al., 2013). Intraperitoneal injection of 5-azacytidine into nude mice bearing subcutaneous xenografts derived from an IDH1-mutant anaplastic astrocytoma specimen resulted in significant tumor regression 14 weeks later, with no signs of re-growth 7 weeks subsequently, despite discontinuation of therapy. These results have implications for phase I pharmacokinetic trials assessing the ability of DNA hypo-methylating drugs like 5-azacytidine to cross the $\mathrm{BBB}$ and reach tumor sites at high enough concentrations and with acceptable side effects. AGI-5198 and ML309 are specific inhibitors of IDH1 R132H, reducing 2-HG levels and significantly decreased the growth of $\mathrm{IDH} 1^{\mathrm{R} 132 \mathrm{H}}$-expressing glioma cells in vitro and human glioma xenografts (Davis et al., 2010; Rohle et al., 2013). Mutant-selective inhibitors of IDH1 (AG-120), IDH2 (AG-221) and both IDH1/2 (AG-881) have entered phase I clinical trials (NCT02073994, NCT02273739, and NCT02481154, respectively) (Chen et al., 2016). Interestingly, a phase I trial of AG-120, an oral inhibitor of mutant IDH1, resulted in stable disease in 10 of 20 patients with IDH1 mutant glioma, with a 6-month clinically beneficial response rate of $25 \%$ (Chen et al., 2016). 


\section{BET Protein Inhibitors}

The acetylation of lysine residues at the N-terminal of histones is associated with activation of transcription through opening of chromatin architecture (Marushige, 1976). This allows for assembly of transcriptional complexes by recruiting BET family proteins such as BRD2, BRD3, and BRD4 (Delmore et al., 2011). The finding, that BET family proteins play a critical role in transcriptional activation and have oncogenic potential, suggested that BET proteins may be potential therapeutic targets in cancers, Several small molecule BET protein inhibitors were therefore developed for testing. One is JQ1, a histone binding module inhibitor that competitively binds to bromodomains with high potency and specificity. JQ1 displaces the BRD4 fusion oncoprotein from chromatin, inducing cell-cycle arrest and initiating apoptosis (Filippakopoulos et al., 2010), suggesting that JQ1 may have wide use in cancer treatment.

Medulloblastoma, the most common malignant brain tumor in children, consists of at least four distinct subtypes, including wingless (WNT), sonic hedgehog ( $\mathrm{SHH})$, and groups 3 and 4 (Cho et al., 2011; Northcott et al., 2011). Amplifications of MYC and MYCN are frequently found in subtypes with the poorest prognosis (Northcott et al., 2012; Bandopadhayay et al., 2014). Notably, MYC protein, a notoriously difficult direct target for novel drug development, together with $\mathrm{SHH}$, is locked within the frame of BET bromodomain inhibition
(Leary and Olson, 2012; Tang et al., 2014). JQ1 treatment of medulloblastoma patients and genetically engineered mouse model-derived medulloblastoma cell lines and xenografts with MYC or MYCN amplifications was found to suppress MYC expression and MYC-associated transcriptional activity, thereby reducing cell viability in medulloblastomas (Bandopadhayay et al., 2014).

Recent molecular and proteomic analyses of autopsy specimens have identified key genetic alterations in DIPG, as well as distinct DIPG subgroups based on activation of the $\mathrm{SHH}$ and MYCN pathways (Saratsis et al., 2014). The high levels of MYCN and SHH in DIPG led to testing the efficacy of sequential therapy with the MYCN and SHH-targeted bromodomain inhibitor JQ1, and the NOTCH-targeted gamma secretase inhibitor MRK003. Dual targeting with JQ1 and MRK003 inhibited DIPG growth and induced apoptosis, suggesting that this therapeutic regimen may be effective (Taylor et al., 2015). More extensive preclinical trials of BET protein inhibitors, as well as the translation of promising results to phase I/II clinical trials in patients with DIPG, are required.

\section{Immunotherapy}

Immunotherapy is rapidly becoming the newest pillar of malignancy treatment, with the potential to harness the potency and specificity of the host immune system. The CNS was

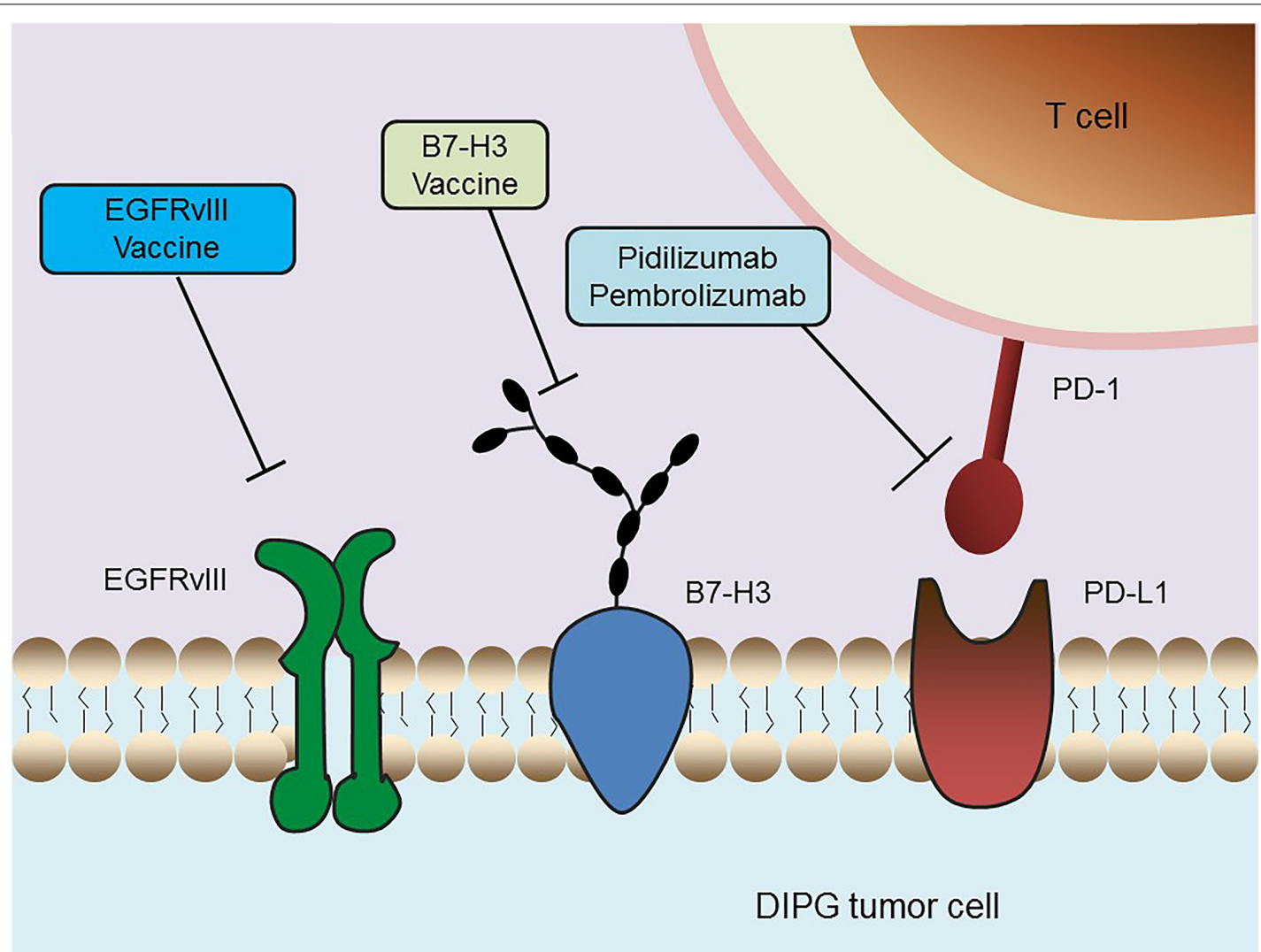

FIGURE 3 | Schematic overview of current immunotherapeutic strategies in DIPG. Multiple immunotherapy methods that are undergoing clinical trials in DIPG, including an EGFRvIII peptide vaccine, a B7-H3 vaccine and anti-PD-1 immune checkpoint inhibitors, are depicted. 


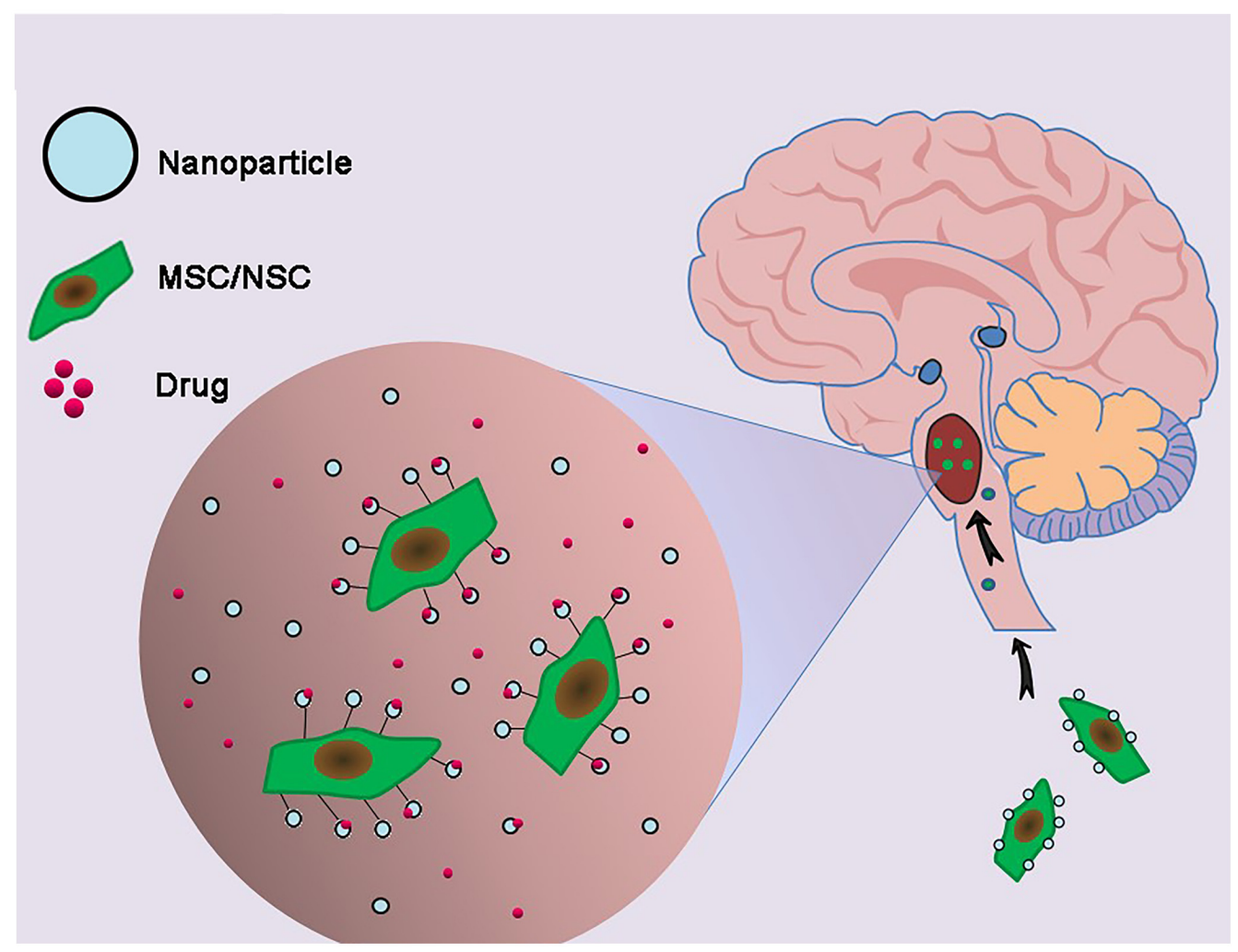

FIGURE 4 | Combination of genetically engineered stem cells and nanotechnology in the treatment of DIPG. The glioma cells-homing behavior of neural stem cells (NSCs) and mesenchymal stem cells (MSCs) was utilized to deliver nanoparticles carrying drugs to DIPG tumor.

historically considered an immune-privileged site because it lacks a conventional lymphatic drainage system (Carson et al., 2006; Vauleon et al., 2010). However, the recent discovery of a lymphatic system within the CNS and novel insights into the mechanisms by which tumor cells evade surveillance by the immune system have stimulated studies of immunotherapy in brain cancers like DIPG (Louveau et al., 2015; Preusser et al., 2015) (Figure 3).

Several studies focused on the identification of DIPG-specific antigens and evaluated their application to vaccine production. EGFR variant III (EGFRvIII) is one of the most common mutations in GBM. The tumor cell selectivity of EGFRvIII was utilized to develop an immunotherapy vaccine for GBM (Li et al., 2010; Staedtke et al., 2016). EGFRvIII was found to be expressed in nearly $50 \%$ of the DIPG samples tested, a percentage high enough for therapeutic targeting (Li et al., 2012). A phase I trial is currently testing treatment with the EGFRvIII peptide vaccine after conventional RT. B7-H3, or CD276, is a type I transmembrane glycoprotein belonging to the B7-CD28 family (Chapoval et al., 2001). This glycoprotein is present in most neuroepithelial tumors, but not in normal neurons, makes this antigen an attractive therapeutic target in CNS tumors. The immunoreactivity of B7-H3 in DIPG specimens was confirmed immunohistochemically (Zhou et al., 2013). The level of expression of B7-H3 was significantly higher in DIPG than in normal brain samples, indicating that this tumor specific antigen (TSA) may serve as a potential therapeutic target in antibody-based immunotherapy. In addition, the gene encoding the neuropeptide prepronociceptin (PNOC) was found to be the most up-regulated gene in pediatric brainstem gangliogliomas relative to non-brainstem gangliogliomas, suggesting that PNOC may have diagnostic significance and that it can be potentially used as an antigen for immunotherapy (Chan et al., 2012).

The immune checkpoint molecules, which are responsible for preventing immune over-activation, also play a key role in antitumor immunity. Cancer cells have developed a particular strategy to up-regulate the expression of such immunosuppressive factors in order to circumvent the host immune response. To date, immune checkpoint inhibitors that can access the blockage of CTLA-4 or PD-1/PD-L1 have been utilized in clinical trials of nearly all types of tumors, showing convincing efficacy in a series of malignancies (Snyder et al., 2014; Le et al., 2015). For example, the humanized antibodies pidilizumab and pembrolizumab, both of which target and inhibit PD-1, are currently undergoing clinical evaluations in DIPG. The clinical trial of pidilizumab is a Phase I/II (NCT01952769) study, whereas the ongoing trial of pembrolizumab has been temporarily suspended due to severe adverse reactions, such as endocrinological, hepatic, gastrointestinal, and dermatological toxicities (NCT02359565). Additional efforts are required to evaluate the safety and efficacy of immune checkpoint inhibitors in the treatment of DIPG. 


\section{Nanoparticle Delivery Systems}

Chemotherapy, even with drugs effective in vitro, may be unsuccessful in vivo due to their inability to penetrate the extremely selective BBB. Moreover, it is difficult to attain a concentration around the tumor site high enough to kill infiltrative tumor cells without damaging ambient normal brain tissues (Pardridge, 2005). Even when enriched within glioma tissues, chemotherapy agents may experience uneven intratumoral distribution due to their entrapment in the extracellular matrix space surrounding neoplastic cells or within intratumoral necrotic pockets, blunting their effects on targeted infiltrative areas. These limitations, however, may be overcome by using stem cell carriers loaded with nanoparticle delivery systems (Figure 4).

The development of nanoparticles, based upon stable elements, polymer nanoparticles and organic nanoparticles, is underway for the treatment of brain tumors, including DIPGs. Trial and error based alterations in their size, composition, and surface chemistry, can result in the development of nanoparticles as a universal platform with multifunctional capabilities, enabling them to meet the different requirements of drug delivery systems (Feng et al., 2011). The glioma cell homing behavior of neural stem cell (NSCs) and mesenchymal stem cells (MSCs) (Benedetti et al., 2000; Wu et al., 2008; Ahmed et al., 2011) can be explored in designing therapeutic carriers. Traditional gene therapy for glioma, relying on the use of viral vectors as transporters to deliver the desired genes to cell carriers (Tyler et al., 2009; Ahmed et al., 2011), has several drawbacks, including infection related cell damage and immune response issues (Everts et al., 2006). Nanoparticles bound to DNA escape these limitations and have shown perspectives for gene delivery into stem cell carriers. For example, polyethylenimine (PEI)-DNA coated silica nanoparticles were developed for gene delivery into hMSCs, with $75 \%$ of hMSCs taking up these particles (Park et al., 2010). Delivery of the hVEGF gene to hMSCs using biodegradable poly beta-amino ester nanoparticles resulted in enhanced VEGF production by these cells (Yang et al., 2010). Although these studies did not specifically evaluate targets for glioma treatment, the concept of nanoparticle-mediated gene delivery to stem cells may be of value if anti-glioma genes can be integrated into nanoparticle transporters. Genetically engineered human adipose tissue-derived mesenchymal stem cells (hAT-MSCs) encoding the tumor necrosis factor-related apoptosis-inducing ligand (TRAIL) were found to control brainstem gliomas, indicating that of non-virally engineered hAT-MSCs are safe and effective against brainstem gliomas and showing that stem-cell-based targeted gene therapy may be clinically applicable (Choi et al., 2010). At present, various multiple nanoparticle formulations are being investigated for the treatment of DIPGs (Bredlau et al., 2017).

\section{FUTURE DIRECTIONS}

Diffuse intrinsic pontine gliomas are malignant tumors with epigenetic characteristics, including histone methylation, histone acetylation, DNA methylation and BET family proteins, indicating that agents targeting epigenetic factors are of great importance in treating DIPG. Understanding the epigenetic landscape of DIPG opens up the opportunity for epigenetic modifiers, which could potentially shift the active genome of this deadly tumor into a silent and regulated state. Indeed, epigenetic modifying therapies are emerging as the most promising class of agents for DIPG. Additional studies are also needed to evaluate the anti-tumor activities resulting from the simultaneous inhibition of multiple epigenetic modifications, as none of those epigenetic alterations can be studied in isolation. Identification of DIPG patient-specific molecular signatures and markers, along with further optimization of epigenetic regulator drugs, will be a major challenge in the development of treatments for DIPG. These efforts may lead to agents with therapeutic benefits in stratified patient populations.

Diffuse intrinsic pontine gliomas show poorer clinical responses to agents that are more effective against other glioma types, suggesting that DIPG is a highly heterogeneous group of tumors that differ in cellular origin and pathogenesis. Efforts are therefore needed to treat tumors with many different molecular genetic alterations located in a site with limited access to therapy. Previous treatment failures may be attributed to several factors, including inadequate drug levels within the tumor due to inability to cross the BBB; testing of single agents or agents with signal pathway redundancies, leading to drug resistance; lack of patient pre-selection; and lack of biomarkers to assess response and off-target effects. Nanotechnology may overcome those limitations and result in improved patient survival rates.

Expedited clinical trials addressing specific targets in small numbers of patients being treated at tertiary medical centers will facilitate the development of larger multicenter randomized clinical trials. In addition, more specific and higher affinity antibodies to tumor antigens that can easily enter the brainstem need to be identified. Thus, combinations of epigenetics, immunotherapy, and nanotechnology may identify models for curing pediatric DIPG.

\section{AUTHOR CONTRIBUTIONS}

WL and YY wrote the manuscript and drew the figures. SC revised the manuscript and modified the figures. QC revised the manuscript according to reviewers' comments. WZ and QL wrote the manuscript and supervised all the work.

\section{ACKNOWLEDGMENTS}

This work was supported by National Natural Science Foundation of China (No. 81572766), Guangdong Innovative and Entepreneurial Research Team Program (No. 2016ZT06S029), and SYSU Young Teachers Training Program (No. 16YKZD14). 


\section{REFERENCES}

Agger, K., Cloos, P. A., Christensen, J., Pasini, D., Rose, S., Rappsilber, J., et al. (2007). UTX and JMJD3 are histone H3K27 demethylases involved in HOX gene regulation and development. Nature 449, 731-734. doi: 10.1038/ nature 06145

Ahmed, A. U., Tyler, M. A., Thaci, B., Alexiades, N. G., Han, Y., Ulasov, I. V., et al. (2011). A comparative study of neural and mesenchymal stem cell-based carriers for oncolytic adenovirus in a model of malignant glioma. Mol. Pharm. 8, 1559-1572. doi: 10.1021/mp200161f

Bagcchi, S. (2015). Panobinostat active against diffuse intrinsic pontine glioma. Lancet Oncol. 16:e267. doi: 10.1016/S1470-2045(15)70230-5

Balss, J., Meyer, J., Mueller, W., Korshunov, A., Hartmann, C., and von Deimling, A. (2008). Analysis of the IDH1 codon 132 mutation in brain tumors. Acta Neuropathol. 116, 597-602. doi: 10.1007/s00401-008-0455-2

Bandopadhayay, P., Bergthold, G., Nguyen, B., Schubert, S., Gholamin, S., Tang, Y., et al. (2014). BET bromodomain inhibition of MYC-amplified medulloblastoma. Clin. Cancer Res. 20, 912-925. doi: 10.1158/1078-0432.CCR13-2281

Barrow, J., Adamowicz-Brice, M., Cartmill, M., MacArthur, D., Lowe, J., Robson, K., et al. (2011). Homozygous loss of ADAM3A revealed by genome-wide analysis of pediatric high-grade glioma and diffuse intrinsic pontine gliomas. Neuro-oncology 13, 212-222. doi: 10.1093/neuonc/ noq158

Barski, A., Cuddapah, S., Cui, K., Roh, T. Y., Schones, D. E., Wang, Z., et al. (2007). High-resolution profiling of histone methylations in the human genome. Cell 129, 823-837. doi: 10.1016/j.cell.2007.05.009

Bartels, U., Hawkins, C., Vezina, G., Kun, L., Souweidane, M., and Bouffet, E. (2011). Proceedings of the diffuse intrinsic pontine glioma (DIPG) Toronto Think Tank: advancing basic and translational research and cooperation in DIPG. J. Neurooncol. 105, 119-125. doi: 10.1007/s11060-0110704-4

Bartels, U., Wolff, J., Gore, L., Dunkel, I., Gilheeney, S., Allen, J., et al. (2014). Phase 2 study of safety and efficacy of nimotuzumab in pediatric patients with progressive diffuse intrinsic pontine glioma. Neuro-oncology 16, 1554-1559. doi: 10.1093/neuonc/nou091

Barton, K. L., Misuraca, K., Cordero, F., Dobrikova, E., Min, H. D., Gromeier, M., et al. (2013). PD-0332991, a CDK4/6 inhibitor, significantly prolongs survival in a genetically engineered mouse model of brainstem glioma. PLoS ONE 8:e77639. doi: 10.1371/journal.pone.0077639

Bender, S., Tang, Y., Lindroth, A. M., Hovestadt, V., Jones, D. T., Kool, M., et al. (2013). Reduced H3K27me3 and DNA hypomethylation are major drivers of gene expression in K27M mutant pediatric high-grade gliomas. Cancer Cell 24, 660-672. doi: 10.1016/j.ccr.2013.10.006

Benedetti, S., Pirola, B., Pollo, B., Magrassi, L., Bruzzone, M. G., Rigamonti, D., et al. (2000). Gene therapy of experimental brain tumors using neural progenitor cells. Nat. Med. 6, 447-450. doi: 10.1038/74710

Bjerke, L., Mackay, A., Nandhabalan, M., Burford, A., Jury, A., Popov, S., et al. (2013). Histone H3.3. mutations drive pediatric glioblastoma through upregulation of MYCN. Cancer Discov. 3, 512-519. doi: 10.1158/2159-8290. CD-12-0426

Borodovsky, A., Salmasi, V., Turcan, S., Fabius, A. W., Baia, G. S., Eberhart, C. G., et al. (2013). 5-azacytidine reduces methylation, promotes differentiation and induces tumor regression in a patient-derived IDH1 mutant glioma xenograft. Oncotarget 4, 1737-1747. doi: 10.18632/oncotarget.1408

Bradley, K. A., Pollack, I. F., Reid, J. M., Adamson, P. C., Ames, M. M., Vezina, G., et al. (2008). Motexafin gadolinium and involved field radiation therapy for intrinsic pontine glioma of childhood: a Children's Oncology Group phase I study. Neuro Oncol. 10, 752-758. doi: 10.1215/152285172008-043

Bradley, K. A., Zhou, T., McNall-Knapp, R. Y., Jakacki, R. I., Levy, A. S., Vezina, G., et al. (2013). Motexafin-gadolinium and involved field radiation therapy for intrinsic pontine glioma of childhood: a children's oncology group phase 2 study. Int. J. Rad. Oncol. Biol. Physics 85, e55-e60. doi: 10.1016/j.ijrobp.2012. 09.004

Bredel, M., Pollack, I. F., Hamilton, R. L., and James, C. D. (1999). Epidermal growth factor receptor expression and gene amplification in high-grade nonbrainstem gliomas of childhood. Clin. Cancer Res. 5, 1786-1792.
Bredlau, A. L., Dixit, S., Chen, C., and Broome, A. M. (2017). Nanotechnology applications for diffuse intrinsic pontine glioma. Curr. Neuropharmacol. 15, 104-115. doi: 10.2174/1570159X14666160223121002

Bricolo, A., and Turazzi, S. (1995). Surgery for gliomas and other mass lesions of the brainstem. Adv. Tech. Stand. Neurosurg 22, 261-341. doi: 10.1007/978-37091-6898-1_5

Bricolo, A., Turazzi, S., Cristofori, L., and Talacchi, A. (1991). Direct surgery for brainstem tumours. Acta Neurochir Suppl. (Wien) 53, 148-158. doi: 10.1007/ 978-3-7091-9183-5_25

Broniscer, A., Baker, J. N., Baker, S. J., Chi, S. N., Geyer, J. R., Morris, E. B., et al. (2010). Prospective collection of tissue samples at autopsy in children with diffuse intrinsic pontine glioma. Cancer-Am. Cancer Soc. 116, 4632-4637. doi: 10.1002/cncr.25405

Brown, Z. Z., Muller, M. M., Jain, S. U., Allis, C. D., Lewis, P. W., and Muir, T. W. (2014). Strategy for "detoxification" of a cancer-derived histone mutant based on mapping its interaction with the methyltransferase PRC2. J. Am. Chem. Soc. 136, 13498-13501. doi: 10.1021/ja5060934

Buczkowicz, P., Hoeman, C., Rakopoulos, P., Pajovic, S., Letourneau, L., Dzamba, M., et al. (2014). Genomic analysis of diffuse intrinsic pontine gliomas identifies three molecular subgroups and recurrent activating ACVR1 mutations. Nat. Genet. 46, 451-456. doi: 10.1038/ng.2936

Carai, A., Mastronuzzi, A., De Benedictis, A., Messina, R., Cacchione, A., Milele, E., et al. (2017). Robot-assisted stereotactic biopsy of diffuse intrinsic pontine glioma: a single-center experience. World Neurosurg 101, 584-588. doi: 10.1016/j.wneu.2017.02.088

Caretti, V., Bugiani, M., Freret, M., Schellen, P., Jansen, M., van Vuurden, D., et al. (2014). Subventricular spread of diffuse intrinsic pontine glioma. Acta Neuropathol. 128, 605-607. doi: 10.1007/s00401-014-1307-x

Caretti, V., Hiddingh, L., Lagerweij, T., Schellen, P., Koken, P. W., Hulleman, E., et al. (2013). WEE1 kinase inhibition enhances the radiation response of diffuse intrinsic pontine gliomas. Mol. Cancer Ther. 12, 141-150. doi: 10.1158/15357163.MCT-12-0735

Carson, M. J., Doose, J. M., Melchior, B., Schmid, C. D., and Ploix, C. C. (2006). CNS immune privilege: hiding in plain sight. Immunol. Rev. 213, 48-65. doi: 10.1111/j.1600-065X.2006.00441.X

Cavalheiro, S., Yagmurlu, K., Da Costa, M. D. S., Nicácio, J. M., Rodrigues, T. P., Chaddad-Neto, F., et al. (2015). Surgical approaches for brainstem tumors in pediatric patients. Child's Nervous Syst. 31, 1815-1840. doi: 10.1007/s00381015-2799-y

Chan, M. H., Kleinschmidt-DeMasters, B. K., Donson, A. M., Birks, D. K., Foreman, N. K., and Rush, S. Z. (2012). Pediatric brainstem gangliogliomas show overexpression of neuropeptide prepronociceptin (PNOC) by microarray and immunohistochemistry. Pediatr. Blood Cancer 59, 1173-1179. doi: 10.1002/ pbc. 24232

Chapoval, A. I., Ni, J., Lau, J. S., Wilcox, R. A., Flies, D. B., Liu, D., et al. (2001). B7$\mathrm{H} 3$ : a costimulatory molecule for T cell activation and IFN-gamma production. Nat. Immunol. 2, 269-274. doi: 10.1038/85339

Chen, J., Yang, J., and Cao, P. (2016). The evolving landscape in the development of isocitrate dehydrogenase mutant inhibitors. Mini Rev. Med. Chem. 16, 1344-1358. doi: 10.2174/1389557516666160609085520

Cho, Y. J., Tsherniak, A., Tamayo, P., Santagata, S., Ligon, A., Greulich, H., et al. (2011). Integrative genomic analysis of medulloblastoma identifies a molecular subgroup that drives poor clinical outcome. J. Clin. Oncol. 29, 1424-1430. doi: 10.1200/JCO.2010.28.5148

Choi, S. A., Hwang, S. K., Wang, K. C., Cho, B. K., Phi, J. H., Lee, J. Y., et al. (2010). Therapeutic efficacy and safety of TRAIL-producing human adipose tissue-derived mesenchymal stem cells against experimental brainstem glioma. Neuro-oncology 13, 61-69. doi: 10.1093/neuonc/noq147

Chornenkyy, Y., Agnihotri, S., Yu, M., Buczkowicz, P., Rakopoulos, P., Golbourn, B., et al. (2015). Poly-ADP-Ribose polymerase as a therapeutic target in pediatric diffuse intrinsic pontine glioma and pediatric high-grade astrocytoma. Mol. Cancer Ther. 14, 2560-2568. doi: 10.1158/1535-7163.MCT15-0282

Chris Beltran, S. S. T. E. (2011). Role of adaptive radiation therapy for pediatric patients with diffuse pontine glioma. J. Appl. Clin. Med. Phys 12, 3421. doi: 10.1120 /jacmp.v12i2.3421

Davis, M., Pragani, R., Popovici-Muller, J., Gross, S., Thorne, N., Salituro, F., et al. (2010). ML309: A Potent Inhibitor of R132H Mutant IDH1 Capable of Reducing 
2-Hydroxyglutarate Production in U87 MG Glioblastoma Cells. Probe Reports form the NIH Molecular Libraries Program. Bethesda, MD: NIH.

Delmore, J. E., Issa, G. C., Lemieux, M. E., Rahl, P. B., Shi, J., Jacobs, H. M., et al. (2011). BET bromodomain inhibition as a therapeutic strategy to target c-Myc. Cell 146, 904-917. doi: 10.1016/j.cell.2011.08.017

Dhalluin, C., Carlson, J. E., Zeng, L., He, C., Aggarwal, A. K., and Zhou, M. M. (1999). Structure and ligand of a histone acetyltransferase bromodomain. Nature 399, 491-496. doi: 10.1038/20974

Donaldson, S. S., Laningham, F., and Fisher, P. G. (2006). Advances toward an understanding of brainstem gliomas. J. Clin. Oncol. 24, 1266-1272. doi: $10.1200 / / C O .2005 .04 .6599$

Ellis, L., Pan, Y., Smyth, G. K., George, D. J., McCormack, C., Williams-Truax, R., et al. (2008). Histone deacetylase inhibitor panobinostat induces clinical responses with associated alterations in gene expression profiles in cutaneous T-cell lymphoma. Clin. Cancer Res. 14, 4500-4510. doi: 10.1158/1078-0432. CCR- $07-4262$

Esteller, M. (2005). Aberrant DNA methylation as a cancer-inducing mechanism. Annu. Rev. Pharmacol. Toxicol. 45, 629-656. doi: 10.1146/annurev.pharmtox. 45.120403.095832

Everts, M., Saini, V., Leddon, J. L., Kok, R. J., Stoff-Khalili, M., Preuss, M. A., et al. (2006). Covalently linked Au nanoparticles to a viral vector: potential for combined photothermal and gene cancer therapy. Nano Lett. 6, 587-591. doi: $10.1021 / \mathrm{nl} 0500555$

Fathi, A. T., and Abdel-Wahab, O. (2012). Mutations in epigenetic modifiers in myeloid malignancies and the prospect of novel epigenetic-targeted therapy. Adv. Hematol. 2012:469592. doi: 10.1155/2012/469592

Feng, B., Matsui, H., and Tomizawa, K. (2011). Nanoparticle-based drug delivery systems for solid brain tumors. Curr. Nanosci. 7, 47-54. doi: 10.2174/ 157341311794480327

Filippakopoulos, P., Qi, J., Picaud, S., Shen, Y., Smith, W. B., Fedorov, O., et al. (2010). Selective inhibition of BET bromodomains. Nature 468, 1067-1073. doi: $10.1038 /$ nature09504

Fontanilla, H. P., Pinnix, C. C., Ketonen, L. M., Woo, S. Y., Vats, T. S., Rytting, M. E., et al. (2012). Palliative reirradiation for progressive diffuse intrinsic pontine glioma. Am. J. Clin. Oncol. 35, 51-57. doi: 10.1097/COC. 0b013e318201a2b7

Fontebasso, A. M., Papillon-Cavanagh, S., Schwartzentruber, J., Nikbakht, H., Gerges, N., Fiset, P. O., et al. (2014). Recurrent somatic mutations in ACVR1 in pediatric midline high-grade astrocytoma. Nat. Genet. 46, 462-466. doi: 10.1038/ng.2950

Freeman, C. R., and Perilongo, G. (1999). Chemotherapy for brain stem gliomas. Childs Nerv. Syst. 15, 545-553. doi: 10.1007/s00381005 0542

Geoerger, B., Hargrave, D., Thomas, F., Ndiaye, A., Frappaz, D., Andreiuolo, F., et al. (2010). Innovative therapies for children with cancer pediatric phase I study of erlotinib in brainstem glioma and relapsing/refractory brain tumors. Neuro-oncology 13, 109-118. doi: 10.1093/neuonc/ noq141

Gilbertson, R. J., Bentley, L., Hernan, R., Junttila, T. T., Frank, A. J., Haapasalo, H., et al. (2002). ERBB receptor signaling promotes ependymoma cell proliferation and represents a potential novel therapeutic target for this disease. Clin. Cancer Res. 8, 3054-3064.

Grasso, C. S., Tang, Y., Truffaux, N., Berlow, N. E., Liu, L., Debily, M., et al. (2015). Functionally defined therapeutic targets in diffuse intrinsic pontine glioma. Nat. Med. 21, 555-559. doi: 10.1038/nm.3855

Guillamo, J. S., Monjour, A., Taillandier, L., Devaux, B., Varlet, P., Haie-Meder, C., et al. (2001). Brainstem gliomas in adults: prognostic factors and classification. Brain 124, 2528-2539. doi: 10.1093/brain/124.12.2528

Gururangan, S., Chi, S. N., Young, P. T., Onar-Thomas, A., Gilbertson, R. J., Vajapeyam, S., et al. (2010). Lack of efficacy of bevacizumab plus irinotecan in children with recurrent malignant glioma and diffuse brainstem glioma: a pediatric brain tumor consortium study. J. Clin. Oncol. 28, 3069-3075. doi: 10.1200/JCO.2009.26.8789

Haas-Kogan, D. A., Banerjee, A., Poussaint, T. Y., Kocak, M., Prados, M. D., Geyer, J. R., et al. (2011). Phase II trial of tipifarnib and radiation in children with newly diagnosed diffuse intrinsic pontine gliomas. Neuro-oncology 13, 298-306. doi: $10.1093 /$ neuonc/noq202
Haffner, M. C., Chaux, A., Meeker, A. K., Esopi, D. M., Gerber, J., Pellakuru, L. G., et al. (2011). Global 5-hydroxymethylcytosine content is significantly reduced in tissue stem/progenitor cell compartments and in human cancers. Oncotarget 2, 627-637. doi: 10.18632/oncotarget.316

Halvorson, K. G., Barton, K. L., Schroeder, K., Misuraca, K. L., Hoeman, C., Chung, A., et al. (2015). A high-throughput in vitro drug screen in a genetically engineered mouse model of diffuse intrinsic pontine glioma identifies BMS754807 as a promising therapeutic agent. PLOS ONE 10:e0118926. doi: 10.1371/ journal.pone.0118926

Hanahan, D., and Weinberg, R. A. (2011). Hallmarks of cancer: the next generation. Cell 144, 646-674. doi: 10.1016/j.cell.2011.02.013

Hashizume, R., Andor, N., Ihara, Y., Lerner, R., Gan, H., Chen, X., et al. (2014). Pharmacologic inhibition of histone demethylation as a therapy for pediatric brainstem glioma. Nat. Med. 20, 1394-1396. doi: 10.1038/nm.3716

Heaphy, C. M., de Wilde, R. F., Jiao, Y., Klein, A. P., Edil, B. H., Shi, C., et al. (2011). Altered telomeres in tumors with ATRX and DAXX mutations. Science 333:425. doi: $10.1126 /$ science. 1207313

Helin, K., and Dhanak, D. (2013). Chromatin proteins and modifications as drug targets. Nature 502, 480-488. doi: 10.1038/nature12751

Helton, K. J., Weeks, J. K., Phillips, N. S., Zou, P., Kun, L. E., Khan, R. B., et al. (2008). Diffusion tensor imaging of brainstem tumors: axonal degeneration of motor and sensory tracts. J. Neurosurg. Pediatr. 1, 270-276. doi: 10.3171/PED/ $2008 / 1 / 4 / 270$

Hennika, T., Hu, G., Olaciregui, N. G., Barton, K. L., Ehteda, A., Chitranjan, A., et al. (2017). Pre-clinical study of panobinostat in xenograft and genetically engineered murine diffuse intrinsic pontine glioma models. PLOS ONE 12:e0169485. doi: 10.1371/journal.pone.0169485

Herz, H. M., Morgan, M., Gao, X., Jackson, J., Rickels, R., Swanson, S. K., et al. (2014). Histone H3 lysine-to-methionine mutants as a paradigm to study chromatin signaling. Science 345, 1065-1070. doi: 10.1126/science.1255104

Jallo, G. I., Volkov, A., Wong, C., Carson, B. S., and Penno, M. B. (2006). A novel brainstem tumor model: functional and histopathological characterization. Childs Nerv. Syst. 22, 1519-1525. doi: 10.1007/s00381-006-0174-8

Khuong-Quang, D. A., Buczkowicz, P., Rakopoulos, P., Liu, X. Y., Fontebasso, A. M., Bouffet, E., et al. (2012). K27M mutation in histone H3.3 defines clinically and biologically distinct subgroups of pediatric diffuse intrinsic pontine gliomas. Acta Neuropathol. 124, 439-447. doi: 10.1007/s00401-0120998-0

Kilburn, L. B., Kocak, M., Schaedeli Stark, F., Meneses-Lorente, G., Brownstein, C., Hussain, S., et al. (2013). Phase I trial of capecitabine rapidly disintegrating tablets and concomitant radiation therapy in children with newly diagnosed brainstem gliomas and high-grade gliomas. Neuro-oncology 15, 759-766. doi: 10.1093/neuonc/nos315

Kitange, G. J., Mladek, A. C., Carlson, B. L., Schroeder, M. A., Pokorny, J. L., Cen, L., et al. (2012). Inhibition of histone deacetylation potentiates the evolution of acquired temozolomide resistance linked to MGMT upregulation in glioblastoma xenografts. Clin. Cancer Res. 18, 4070-4079. doi: 10.1158/10780432.CCR-12-0560

Kyoshima, K., Kobayashi, S., Gibo, H., and Kuroyanagi, T. (1993). A study of safe entry zones via the floor of the fourth ventricle for brain-stem lesions, Report of three cases. J. Neurosurg. 78, 987-993. doi: 10.3171/jns.1993.78.6.0987

Landolfi, J. C., Thaler, H. T., and DeAngelis, L. M. (1998). Adult brainstem gliomas. Neurology 51, 1136-1139. doi: 10.1212/WNL.51.4.1136

Lawton, M. T., Quinones-Hinojosa, A., and Jun, P. (2006). The supratonsillar approach to the inferior cerebellar peduncle: anatomy, surgical technique, and clinical application to cavernous malformations. Neurosurgery 59, ONS244ONS251. doi: 10.1227/01.NEU.0000232767.16809.68

Le, D. T., Uram, J. N., Wang, H., Bartlett, B. R., Kemberling, H., Eyring, A. D., et al. (2015). PD-1 blockade in tumors with mismatch-repair deficiency. N. Engl. J. Med. 372, 2509-2520. doi: 10.1056/NEJMoa1500596

Leary, S. E., and Olson, J. M. (2012). The molecular classification of medulloblastoma: driving the next generation clinical trials. Curr. Opin. Pediatr. 24, 33-39. doi: 10.1097/MOP.0b013e32834ec106

Lewis, P. W., and Allis, C. D. (2013). Poisoning the "histone code" in pediatric gliomagenesis. Cell Cycle 12, 3241-3242. doi: 10.4161/cc.26356

Lewis, P. W., Muller, M. M., Koletsky, M. S., Cordero, F., Lin, S., Banaszynski, L. A., et al. (2013). Inhibition of PRC2 activity by a gain-of-function H3 mutation 
found in pediatric glioblastoma. Science 340, 857-861. doi: 10.1126/science. 1232245

Li, G., Mitra, S., and Wong, A. J. (2010). The epidermal growth factor variant III peptide vaccine for treatment of malignant gliomas. Neurosurg. Clin. N. Am. 21, 87-93. doi: 10.1016/j.nec.2009.08.004

Li, G., Mitra, S. S., Monje, M., Henrich, K. N., Bangs, C. D., Nitta, R. T., et al. (2012). Expression of epidermal growth factor variant III (EGFRvIII) in pediatric diffuse intrinsic pontine gliomas. J. Neurooncol. 108, 395-402. doi: 10.1007/ s11060-012-0842-3

Liu, A. K., Macy, M. E., and Foreman, N. K. (2009). Bevacizumab as therapy for radiation necrosis in four children with pontine gliomas. Int. J. Radiat. Oncol. Biol. Phys. 75, 1148-1154. doi: 10.1016/j.ijrobp.2008.12.032

Louveau, A., Smirnov, I., Keyes, T. J., Eccles, J. D., Rouhani, S. J., Peske, J. D., et al. (2015). Structural and functional features of central nervous system lymphatic vessels. Nature 523, 337-341. doi: 10.1038/nature14432

Maria, B. L., Rehder, K., Eskin, T. A., Hamed, L. M., Fennell, E. B., Quisling, R. G., et al. (1993). Brainstem glioma: I. Pathology, clinical features, and therapy. J. Child Neurol. 8, 112-128. doi: 10.1177/088307389300800203

Marushige, K. (1976). Activation of chromatin by acetylation of histone side chains. Proc. Natl. Acad. Sci. U.S.A. 73, 3937-3941. doi: 10.1073/pnas.73.11.3937

Maze, I., Noh, K. M., and Allis, C. D. (2013). Histone regulation in the CNS: basic principles of epigenetic plasticity. Neuropsychopharmacology 38, 3-22. doi: $10.1038 /$ npp. 2012.124

Milde, T., Kleber, S., Korshunov, A., Witt, H., Hielscher, T., Koch, P., et al. (2011). A novel human high-risk ependymoma stem cell model reveals the differentiation-inducing potential of the histone deacetylase inhibitor Vorinostat. Acta Neuropathol. 122, 637-650. doi: 10.1007/s00401-011-0866-3

Mohammad, F., Weissmann, S., Leblanc, B., Pandey, D. P., Højfeldt, J. W., Comet, I., et al. (2017). EZH2 is a potential therapeutic target for H3K27Mmutant pediatric gliomas. Nat. Med 2010:18. doi: 10.1038/nm.4293

Morales, L. M. A., and Kieran, M. W. (2017). Epigenetics in clinical management of children and adolescents with brain tumors. Curr Cancer Drug Targets doi: 10.2174/1568009617666170203164456 [Epub ahead of print].

Morin, R. D., Johnson, N. A., Severson, T. M., Mungall, A. J., An, J., Goya, R., et al. (2010). Somatic mutations altering EZH2 (Tyr641) in follicular and diffuse large B-cell lymphomas of germinal-center origin. Nat. Genet. 42, 181-185. doi: $10.1038 / \mathrm{ng} .518$

Morin, R. D., Mendez-Lago, M., Mungall, A. J., Goya, R., Mungall, K. L., Corbett, R. D., et al. (2011). Frequent mutation of histone-modifying genes in nonHodgkin lymphoma. Nature 476, 298-303. doi: 10.1038/nature10351

Northcott, P. A., Korshunov, A., Witt, H., Hielscher, T., Eberhart, C. G., Mack, S., et al. (2011). Medulloblastoma comprises four distinct molecular variants. J. Clin. Oncol. 29, 1408-1414. doi: 10.1200/JCO.2009.27.4324

Northcott, P. A., Shih, D. J., Peacock, J., Garzia, L., Morrissy, A. S., Zichner, T., et al. (2012). Subgroup-specific structural variation across 1,000 medulloblastoma genomes. Nature 488, 49-56. doi: 10.1038/nature11327

Orr, B. A., Haffner, M. C., Nelson, W. G., Yegnasubramanian, S., and Eberhart, C. G. (2012). Decreased 5-hydroxymethylcytosine is associated with neural progenitor phenotype in normal brain and shorter survival in malignant glioma. PLoS ONE 7:e41036. doi: 10.1371/journal.pone.0041036

Ostrom, Q. T., Gittleman, H., Fulop, J., Liu, M., Blanda, R., Kromer, C., et al. (2015). CBTRUS statistical report: primary brain and central nervous system tumors diagnosed in the united states in 2008-2012. Neuro-oncology 17, iv1-iv62. doi: 10.1093/neuonc/nov189

Pardridge, W. M. (2005). Molecular biology of the blood-brain barrier. Mol. Biotechnol. 30, 57-70. doi: 10.1385/MB

Park, J. S., Na, K., Woo, D. G., Yang, H. N., Kim, J. M., Kim, J. H., et al. (2010). Non-viral gene delivery of DNA polyplexed with nanoparticles transfected into human mesenchymal stem cells. Biomaterials 31, 124-132. doi: 10.1016/ j.biomaterials.2009.09.023

Paugh, B. S., Qu, C., Jones, C., Liu, Z., Adamowicz-Brice, M., Zhang, J., et al. (2010). Integrated molecular genetic profiling of pediatric high-grade gliomas reveals key differences with the adult disease. J. Clin. Oncol. 28, 3061-3068. doi: 10.1200/JCO.2009.26.7252

Paugh, B. S., Zhu, X., Qu, C., Endersby, R., Diaz, A. K., Zhang, J., et al. (2013). Novel oncogenic PDGFRA mutations in pediatric high-grade gliomas. Cancer Res. 73, 6219-6229. doi: 10.1158/0008-5472.CAN-13-1491
Piunti, A., Hashizume, R., Morgan, M. A., Bartom, E. T., Horbinski, C. M., Marshall, S. A., et al. (2017). Therapeutic targeting of polycomb and BET bromodomain proteins in diffuse intrinsic pontine gliomas. Nat. Med. 423, 493-500. doi: 10.1038/nm.4296

Pollack, I. F., Stewart, C. F., Kocak, M., Poussaint, T. Y., Broniscer, A., Banerjee, A., et al. (2011). A phase II study of gefitinib and irradiation in children with newly diagnosed brainstem gliomas: a report from the pediatric brain tumor consortium. Neuro Oncol. 13, 290-297. doi: 10.1093/neuonc/ noq199

Preusser, M., Lim, M., Hafler, D. A., Reardon, D. A., and Sampson, J. H. (2015). Prospects of immune checkpoint modulators in the treatment of glioblastoma. Nat. Rev. Neurol. 11, 504-514. doi: 10.1038/nrneurol.2015.139

Puget, S., Beccaria, K., Blauwblomme, T., Roujeau, T., James, S., Grill, J., et al. (2015). Biopsy in a series of 130 pediatric diffuse intrinsic pontine gliomas. Childs Nerv. Syst. 31, 1773-1780. doi: 10.1007/s00381-015-2832-1

Puget, S., Philippe, C., Bax, D. A., Job, B., Varlet, P., Junier, M. P., et al. (2012). Mesenchymal transition and PDGFRA amplification/mutation are key distinct oncogenic events in pediatric diffuse intrinsic pontine gliomas. PLoS ONE 7:e30313. doi: 10.1371/journal.pone.0030313

Puissant, A., Frumm, S. M., Alexe, G., Bassil, C. F., Qi, J., Chanthery, Y. H., et al. (2013). Targeting MYCN in neuroblastoma by BET bromodomain inhibition. Cancer Discov. 3, 308-323. doi: 10.1158/2159-8290.CD-12-0418

Recinos, P. F., Sciubba, D. M., and Jallo, G. I. (2007). Brainstem tumors: where are we today? Pediatr. Neurosurg. 43, 192-201. doi: 10.1159/000098831

Rineer, J., Schreiber, D., Choi, K., and Rotman, M. (2010). Characterization and outcomes of infratentorial malignant glioma: a population-based study using the Surveillance Epidemiology and End-Results database. Radiother. Oncol. 95, 321-326. doi: 10.1016/j.radonc.2010.04.007

Robison, N. J., and Kieran, M. W. (2014). Diffuse intrinsic pontine glioma: a reassessment. J. Neurooncol. 119, 7-15. doi: 10.1007/s11060-014-1448-8

Rohle, D., Popovici-Muller, J., Palaskas, N., Turcan, S., Grommes, C., Campos, C., et al. (2013). An inhibitor of mutant IDH1 delays growth and promotes differentiation of glioma cells. Science 340, 626-630. doi: 10.1126/science. 1236062

Roos, D. E., and Smith, J. G. (2014). Randomized trial on radiotherapy for paediatric diffuse intrinsic pontine glioma (DIPG). Radiother. Oncol. 113:425. doi: 10.1016/j.radonc.2014.08.041

Rubin, G., Michowitz, S., Horev, G., Herscovici, Z., Cohen, I. J., Shuper, A., et al. (1998). Pediatric brain stem gliomas: an update. Childs Nerv. Syst. 14, 167-173. doi: $10.1007 / \mathrm{s} 003810050205$

Salmaggi, A., Fariselli, L., Milanesi, I., Lamperti, E., Silvani, A., Bizzi, A., et al. (2008). Natural history and management of brainstem gliomas in adults. A retrospective Italian study. J. Neurol. 255, 171-177. doi: 10.1007/s00415-0080589-0

Saratsis, A. M., Kambhampati, M., Snyder, K., Yadavilli, S., Devaney, J. M., Harmon, B., et al. (2014). Comparative multidimensional molecular analyses of pediatric diffuse intrinsic pontine glioma reveals distinct molecular subtypes. Acta Neuropathol. 127, 881-895. doi: 10.1007/s00401-013-1218-2

Schubeler, D. (2015). Function and information content of DNA methylation. Nature 517, 321-326. doi: 10.1038/nature14192

Schwartzentruber, J., Korshunov, A., Liu, X. Y., Jones, D. T., Pfaff, E., Jacob, K., et al. (2012). Driver mutations in histone H3.3 and chromatin remodelling genes in paediatric glioblastoma. Nature 482, 226-231. doi: 10.1038/nature10833

Sirachainan, N., Pakakasama, S., Visudithbhan, A., Chiamchanya, S., Tuntiyatorn, L., Dhanachai, M., et al. (2008). Concurrent radiotherapy with temozolomide followed by adjuvant temozolomide and cis-retinoic acid in children with diffuse intrinsic pontine glioma. Neuro Oncol. 10, 577-582. doi: 10.1215/15228517-2008-025

Skene, P. J., and Henikoff, S. (2013). Histone variants in pluripotency and disease. Development 140, 2513-2524. doi: 10.1242/dev.091439

Snyder, A., Makarov, V., Merghoub, T., Yuan, J., Zaretsky, J. M., Desrichard, A., et al. (2014). Genetic basis for clinical response to CTLA-4 blockade in melanoma. N. Engl. J. Med. 371, 2189-2199. doi: 10.1056/NEJMoa1406498

Solomon, D. A., Wood, M. D., Tihan, T., Bollen, A. W., Gupta, N., Phillips, J. J., et al. (2016). Diffuse midline gliomas with histone H3-K27M mutation: a series of 47 cases assessing the spectrum of morphologic variation and association genetic alterations. Brain Pathol. 26, 569-580. doi: 10.1111/bpa.12336 
Staedtke, V., Bai, R. Y., and Laterra, J. (2016). Investigational new drugs for brain cancer. Exp. Opin. Investig. Drugs 25, 937-956. doi: 10.1080/13543784.2016. 1182497

Sturm, D., Witt, H., Hovestadt, V., Khuong-Quang, D. A., Jones, D. T., Konermann, C., et al. (2012). Hotspot mutations in H3F3A and IDH1 define distinct epigenetic and biological subgroups of glioblastoma. Cancer Cell 22, 425-437. doi: 10.1016/j.ccr.2012.08.024

Susheela, S. P., Revannasiddaiah, S., Muzumder, S., Mallarajapatna, G., Kallur, K., and Basavalingaiah, A. S. (2013). Re-irradiation with hypofractionated stereotactic robotic radiotherapy for salvage in adult patients with brainstem glioma. Ecancermedicalscience 7:366. doi: 10.3332/ecancer. 2013.366

Tan, J., Yang, X., Zhuang, L., Jiang, X., Chen, W., Lee, P. L., et al. (2007). Pharmacologic disruption of polycomb-repressive complex 2-mediated gene repression selectively induces apoptosis in cancer cells. Genes Dev. 21, 1050-1063. doi: 10.1101/gad.1524107

Tang, Y., Gholamin, S., Schubert, S., Willardson, M. I., Lee, A., Bandopadhayay, P., et al. (2014). Epigenetic targeting of Hedgehog pathway transcriptional output through BET bromodomain inhibition. Nat. Med. 20, 732-740. doi: 10.1038/ nm.3613

Taylor, I. C., Hütt-Cabezas, M., Brandt, W. D., Kambhampati, M., Nazarian, J., Chang, H. T., et al. (2015). Disrupting NOTCH slows diffuse intrinsic pontine glioma growth, enhances radiation sensitivity, and shows combinatorial efficacy with bromodomain inhibition. J. Neuropathol. Exp. Neurol. 74, 778-790. doi: 10.1097/NEN.0000000000000216

Taylor, K. R., Mackay, A., Truffaux, N., Butterfield, Y. S., Morozova, O., Philippe, C., et al. (2014). Recurrent activating ACVR1 mutations in diffuse intrinsic pontine glioma. Nat. Genet. 46, 457-461. doi: 10.1038/ng.2925

Truffaux, N., Philippe, C., Paulsson, J., Andreiuolo, F., Guerrini-Rousseau, L., Cornilleau, G., et al. (2015). Preclinical evaluation of dasatinib alone and in combination with cabozantinib for the treatment of diffuse intrinsic pontine glioma. Neuro-oncology 17, 953-964. doi: 10.1093/neuonc/nou330

Turcan, S., Fabius, A. W., Borodovsky, A., Pedraza, A., Brennan, C., Huse, J., et al. (2013). Efficient induction of differentiation and growth inhibition in IDH1 mutant glioma cells by the DNMT inhibitor decitabine. Oncotarget 4, 1729-1736. doi: 10.18632/oncotarget.1412

Turcan, S., Rohle, D., Goenka, A., Walsh, L. A., Fang, F., Yilmaz, E., et al. (2012). IDH1 mutation is sufficient to establish the glioma hypermethylator phenotype. Nature 483, 479-483. doi: 10.1038/nature10866

Tyler, M. A., Ulasov, I. V., Sonabend, A. M., Nandi, S., Han, Y., Marler, S., et al. (2009). Neural stem cells target intracranial glioma to deliver an oncolytic adenovirus in vivo. Gene Ther. 16, 262-278. doi: 10.1038/gt.2008.165

Varambally, S., Cao, Q., Mani, R. S., Shankar, S., Wang, X., Ateeq, B., et al. (2008). Genomic loss of microRNA-101 leads to overexpression of histone methyltransferase EZH2 in cancer. Science 322, 1695-1699. doi: 10.1126/ science. 1165395

Varambally, S., Dhanasekaran, S. M., Zhou, M., Barrette, T. R., Kumar-Sinha, C., Sanda, M. G., et al. (2002). The polycomb group protein EZH2 is involved in progression of prostate cancer. Nature 419, 624-629. doi: 10.1038/nature 01075

Vauleon, E., Avril, T., Collet, B., Mosser, J., and Quillien, V. (2010). Overview of cellular immunotherapy for patients with glioblastoma. Clin. Dev. Immunol. 2010:18. doi: 10.1155/2010/689171

Veringa, S. J., Biesmans, D., van Vuurden, D. G., Jansen, M. H., Wedekind, L. E., Horsman, I., et al. (2013). In vitro drug response and efflux transporters associated with drug resistance in pediatric high grade glioma and diffuse intrinsic pontine glioma. PLOS ONE 8:e61512. doi: 10.1371/journal.pone. 0061512

Wadhwa, E., and Nicolaides, T. (2016). bromodomain inhibitor review: bromodomain and extra-terminal family protein inhibitors as a potential new therapy in central nervous system tumors. Cureus 8:e620. doi: 10.7759/ cureus. 620

Wakabayashi, T., Yoshida, J., Mizuno, M., Kito, A., and Sugita, K. (1992). Effectiveness of interferon- $\beta, \mathrm{ACNU}$, and radiation therapy in pediatric patients with brainstem glioma. Neurol. Med. Chir. 32, 942-946.

Wang, Z. J., Ge, Y., Altinok, D., Poulik, J., Sood, S., Taub, J. W., et al. (2017). Concomitant use of panobinostat and reirradiation in progressive DIPG: report of 2 cases. J. Pediatr. Hematol. Oncol. doi: 10.1097/MPH.0000000000000806 [Epub ahead of print].

Warren, K. E., Gururangan, S., Geyer, J. R., McLendon, R. E., Poussaint, T. Y., Wallace, D., et al. (2012). A phase II study of O6-benzylguanine and temozolomide in pediatric patients with recurrent or progressive high-grade gliomas and brainstem gliomas: a pediatric brain tumor consortium study. J. Neurooncol. 106, 643-649. doi: 10.1007/s11060-011-0709-z

Wiese, M., Schill, F., Sturm, D., Pfister, S., Hulleman, E., Johnsen, S. A., et al. (2016). No significant cytotoxic effect of the EZH2 inhibitor tazemetostat (EPZ-6438) on pediatric glioma cells with wildtype histone 3 or mutated histone 3.3. Klin. Padiatr. 228, 113-117. doi: 10.1055/s-0042-105292

Wolff, J. E., Rytting, M. E., Vats, T. S., Zage, P. E., Ater, J. L., Woo, S., et al. (2012). Treatment of recurrent diffuse intrinsic pontine glioma: the $\mathrm{MD}$ anderson cancer center experience. J. Neuro-Oncol. 106, 391-397. doi: 10.1007/s11060011-0677-3

Wu, G., Broniscer, A., McEachron, T. A., Lu, C., Paugh, B. S., Becksfort, J., et al. (2012). Somatic histone H3 alterations in pediatric diffuse intrinsic pontine gliomas and non-brainstem glioblastomas. Nat. Genet. 44, 251-253. doi: 10.1038/ng.1102

Wu, X., Hu, J., Zhou, L., Mao, Y., Yang, B., Gao, L., et al. (2008). In vivo tracking of superparamagnetic iron oxide nanoparticle-labeled mesenchymal stem cell tropism to malignant gliomas using magnetic resonance imaging. Laboratory investigation. J. Neurosurg. 108, 320-329. doi: 10.3171/JNS/2008/108/2/0320

Yang, F., Cho, S. W., Son, S. M., Bogatyrev, S. R., Singh, D., Green, J. J., et al. (2010). Genetic engineering of human stem cells for enhanced angiogenesis using biodegradable polymeric nanoparticles. Proc. Natl. Acad. Sci. U.S.A. 107, 3317-3322. doi: 10.1073/pnas.0905432106

Zarghooni, M., Bartels, U., Lee, E., Buczkowicz, P., Morrison, A., Huang, A., et al. (2010). Whole-genome profiling of pediatric diffuse intrinsic pontine gliomas highlights platelet-derived growth factor receptor alpha and poly (ADP-ribose) polymerase as potential therapeutic targets. J. Clin. Oncol. 28, 1337-1344. doi: $10.1200 /$ JCO.2009.25.5463

Zhang, J., Wu, G., Miller, C. P., Tatevvossian, R. G., Dalton, J. D., Tang, B., et al. (2013). Whole-genome sequencing identifies genetic alterations in pediatric low-grade gliomas. Nat. Genet. 45, 602-612. doi: 10.1038/ng.2611

Zhang, L., Chen, L. H., Wan, H., Yang, R., Wang, Z., Feng, J., et al. (2014). Exome sequencing identifies somatic gain-of-function PPM1D mutations in brainstem gliomas. Nat. Genet. 46, 726-730. doi: 10.1038/ng.2995

Zhou, Z., Luther, N., Ibrahim, G. M., Hawkins, C., Vibhakar, R., Handler, M. H., et al. (2013). B7-H3, a potential therapeutic target, is expressed in diffuse intrinsic pontine glioma. J. Neurooncol. 111, 257-264. doi: 10.1007/s11060-0121021-2

Conflict of Interest Statement: The authors declare that the research was conducted in the absence of any commercial or financial relationships that could be construed as a potential conflict of interest.

Copyright (C) 2017 Long, Yi, Chen, Cao, Zhao and Liu. This is an open-access article distributed under the terms of the Creative Commons Attribution License (CC BY). The use, distribution or reproduction in other forums is permitted, provided the original author(s) or licensor are credited and that the original publication in this journal is cited, in accordance with accepted academic practice. No use, distribution or reproduction is permitted which does not comply with these terms. 